\title{
OPELINA ROLLEMBERG: EDUCADORA PROTAGONISTA DA ENFERMAGEM SERGIPANA
}

\author{
Kelly Cristina Resende Rocha ${ }^{1}$, Sandro Rogério Almeida Matos Júnior ${ }^{2}$, Angela Maria de Melo Sá Barros ${ }^{3}$, \\ Pacita Geovana Gama de Sousa Aperibense ${ }^{4}$, Simone Silveira Amorim ${ }^{5}$
}

\begin{abstract}
${ }^{1}$ Mestranda do Programa de Pós-Graduação em Educação da Universidade Tiradentes - UNIT, Aracaju, SE. É Bolsista PROCAPS/FAPITEC/UNIT. E-mail: kellyrocha05@gmail.com. ORCID: https://orcid.org/0000-0001-9258-109X

${ }^{2}$ Graduado em Enfermagem pela Universidade Tiradentes - UNIT. Integrante do Grupo de Pesquisa História da Educação do Nordeste (GPHEN) do Programa de Pós-Graduação em Educação da Universidade Tiradentes - UNIT, Aracaju, SE. E-mail: sandrojunior170793@gmail.com

${ }^{3}$ Doutoranda do Programa de Pós-Graduação em Enfermagem da Escola de Enfermagem Anna Nery da Universidade Federal do Rio de Janeiro - UFRJ, RJ. Docente substituta do Curso de Enfermagem da Escola de Enfermagem Anna Nery- EEAN/UFRJ . E-mail: angelsamelo@hotmail.com

${ }^{4}$ Doutora em Enfermagem pela Escola de Enfermagem Anna Nery/UFRJ. Docente do curso de enfermagem da UFRJ (campus Macaé- Professor Aloísio Teixeira), Membro do Núcleo de Pesquisa de História da Enfermagem Brasileira (Nuphebras) .E-mail: pacitageovana@yahoo.com.br.ORCID: http://orcid.org/0000-0002-3176-2134

${ }^{5}$ Pós-Doutora em Educação pela University of Boston/Massachusetts. Docente permanente do Programa de PósGraduação em Educação da Universidade Tiradentes - UNIT, está vinculada ao ITP/Unit e ao Tiradentes Institute/Boston. Email: amorim simone@hotmail.com. ORCID: https://orcid.org/0000-0002-1305-6017
\end{abstract}

\section{RESUMO}

O objetivo deste artigo é apresentar a trajetória profissional de Opelina Rollemberg (1906-1966), considerada uma das pioneiras da enfermagem sergipana, buscando destacar as contribuições da referida enfermeira para o processo formativo da enfermagem em Sergipe e abordar sobre sua ação profissional no que diz respeito à promoção da saúde e no contexto historiográfico da enfermagem sergipana. Trata-se de um estudo de natureza histórico documental, a partir de fontes documentais e icnográficas, além do levantamento bibliográfico em bases de dados científicas como Scielo, Biblioteca Virtual da Saúde (BVS) e Pubmed. Incialmente, verificou-se vestígios da história de sua vida, seguidos do processo de formação e atuação profissional no Brasil. Identificou-se que ela foi aluna da Escola de Enfermagem Anna Nery, onde seguiu na carreira docente na referida Escola. Contudo, recebeu convite do Departamento Nacional de Saúde Pública para atuar na organização da saúde pública do Estado. Ao retornar a Sergipe, contribuiu no Projeto de Saúde Sanitária orientado pelo modelo Nacional. Também foi pioneira e gestora do primeiro curso de Enfermeiras-visitadoras do Estado. Nesse contexto é possível conhecer a trajetória de uma mulher, professora e enfermeira, que teve sua vida dedicada aos estudos e ao trabalho e que contribuiu, enquanto educadora, para a organização da saúde pública em Sergipe e em outras localidades da nação.

Palavras-chave: História da Enfermagem. Biografia. Educação. Enfermagem.

\section{OPELINA ROLLEMBERG: LEADING EDUCATOR OF SERGIPE NURSING}

\section{ABSTRACT}

The objective of this article is to present the professional trajectory of Opelina Rollemberg (1906-1966), considered one of the pioneers of Sergipe nursing, seeking to highlight the contributions of this nurse to the nursing training process in Sergipe and to discuss her professional contribution to the promotion health and in the historiographic context of Sergipe nursing. It is a documentary historical study, based on documentary and icnographic sources, as well as a bibliographic survey in scientific databases such as Scielo, Virtual Health Library (VHL) and Pubmed. Initially, there were vestiges of the history of his life, followed by the process of formation and professional activity in Brazil. She was a student at the Anna Nery School of Nursing, where she continued her teaching career at the School. However, it was invited by the National Department of Public Health to work in the State Public Health organization. When she returned 
to Sergipe, he contributed to the health care project guided by the National model. She was also the pioneer and manager of the first course of State Nurse-visitors. In this context it is possible to infer about a woman, teacher and nurse who has had her life dedicated to studies and has effectively contributed, as an educator, in the organization of public health sergipana and in other localities of the nation.

Keywords: History of Nursing. Biography. Education. Nursing.

\section{OPELINA ROLLEMBERG: PROTAGONISTA EDUCADORA DE ENFERMERÍA SERGIPANA}

\section{RESUMEN}

El objetivo de este artículo es presentar la trayectoria profesional de Opelina Rollemberg (1906-1966), considerada una de las pioneras de la enfermería sergipana, buscando destacar las contribuciones de la referida enfermera al proceso formativo de la enfermería en Sergipe y abordar sobre su contribución profesional a la promoción de la salud y en el contexto historiográfico de la enfermería sergipana. Se trata de un estudio de naturaleza histórica documental, a partir de fuentes documentales e icnográficas, además del levantamiento bibliográfico en bases de datos científicos como Scielo, Biblioteca Virtual de la Salud (BVS) y Pubmed. En principio, se verificaron vestigios de la historia de su vida, seguidos del proceso de formación y actuación profesional en Brasil. Fue alumna de la Escuela de Enfermería Anna Nery, donde siguió en la carrera docente en la referida Escuela. Sin embargo, recibió invitación del Departamento Nacional de Salud Pública para actuar en la organización de la Salud Pública del Estado. Cuando regresó a Sergipe, contribuyó en el proyecto de salud sanitaria orientado por el modelo Nacional. También fue pionera y gestora del primer curso de Enfermeras-visitadoras del Estado. En ese contexto es posible inferir sobre una mujer, profesora y enfermera que tuvo su vida dedicada a los estudios y de modo efectivo contribuyó, como educadora, en la organización de la salud pública sergipana y en otras localidades de la nación.

Palabras-clave: Historia de la Enfermería. Biografía. Educación. Enfermería.

\section{INTRODUÇÃO}

O objetivo deste artigo é apresentar a sergipana Opelina Rollemberg como enfermeira pioneira e destacar as suas contribuições para o desenvolvimento da enfermagem em Sergipe. ${ }^{1}$ Este estudo está inserido no campo da História da Educação, a partir da trajetória profissional da referida enfermeira devido ao fato de ter iniciado sua formação como professora normalista e posteriormente afirmando-se como enfermeira e docente em saúde.

Assim, este estudo adentra ao campo da História da Educação onde, de acordo Nóvoa (1992, p. 211):

\begin{abstract}
A História da Educação não é importante apenas porque nos fornece a 'memória dos percursos educacionais' (que alguns casos se pode revestir de uma certa exemplaridade)
\end{abstract}

\footnotetext{
${ }^{1}$ Este estudo tem origem no Trabalho de Conclusão de Curso (TCC) desenvolvido na graduação em Enfermagem na Universidade Tiradentes em (2017) pelos pesquisadores ${ }^{1} \mathrm{e}^{2}$. É parte da dissertação em andamento da pesquisadora ${ }^{1}$, na linha Educação e Formação Docente do Programa de Pós-graduação em Educação da Universidade Tiradentes.
}

mas sobretudo porque nos permite compreender que não há nenhum determinismo na evolução dos sistemas educativos, das ideias pedagógicas ou das práticas escolares: tudo é produto de uma construção social.

Insere-se no âmbito da História Cultural,
matriz metodológica constituída como
instrumento essencial para compreensão de
realidades sociais ao operar com seus agentes e
contextos, pois "[...] a história cultural, tal como a
entendemos, tem por principal objeto identificar
o modo como em diferentes lugares e momentos
uma determinada realidade social é construída,
pensada, dada a ler" (CHARTIER, 1990, p. 16-17).
É sob essa matriz que será discutida a
construção das políticas sociais e de saúde em
Sergipe, perpassando pela atuação das suas
primeiras enfermeiras. Desta maneira, é
necessário compreender a trajetória dessas
profissionais, tendo como foco a atuação de
Opelina Rollemberg, que dedicaram seus esforços
para desenvolvimento da educação e da saúde,


contribuindo para a compreensão do desenvolvimento da enfermagem no país. É nesse sentido que se insere a importância do estudo de trajetórias de vida no âmbito da enfermagem, pois,

As biografias ou trajetórias
de vida das enfermeiras
têm sido utilizadas na
educação de enfermagem
com várias finalidades -
ressaltar o
desenvolvimento de uma
área profissional
específica; orientar a
criação de escolas de
enfermagem e associações
profissionais; criar teorias
de enfermagem; investigar
os avanços sociais e
políticos da profissão
(PADILHA; NELSON;
BORENSTEIN, 2011, p.
243).

Nesse intento, pesquisadores enriquecem esse campo científico a partir de conhecimentos sobre a trajetória de intelectuais e profissionais que se destacaram pelo envolvimento, sobretudo, com a educação e sua capacidade transversal de aproximar a epistemologia aos saberes de uma determinada realidade social ou temporal.

Uma dessas contribuições está no livro A trajetória de Alfredo Montes (1848-1906): representações da configuração do trabalho docente no ensino secundário em Sergipe (AMORIM, 2009). Esta pesquisa evidencia que é possível investigar a trajetória de vida de uma pessoa, identificando suas contribuições e representações, bem como compreender o contexto da realidade vivenciada em suas configurações, sobretudo no campo educacional.

Descrever a trajetória profissional de um indivíduo requer esforço e disposição por parte do pesquisador. É necessário estabelecer o diálogo entre as fontes e os teóricos escolhidos para dar sustentação à pesquisa e, principalmente, considerar o tempo vivenciado pelo personagem. Assim sendo, o pesquisador, ao questionar suas fontes, poderá fazer suposições, contar uma história, o que requer muito cuidado, pois "[...] uma vida é inseparavelmente 0 conjunto dos acontecimentos de uma existência individual concebida como uma história e o relato dessa história" (BOURDIEU, 1996, p. 183).

Neste sentido, a trajetória profissional de uma pessoa está atrelada à sociedade ou campo social. Assim, entende-se que toda profissão é uma reprodução social e tem suas finalidades e, entre elas, a de contribuir para a melhoria da vida da população (BOURDIEU, 2007). Assim, é necessário conhecer o indivíduo, o contexto em que viveu e o que o motivou na escolha da profissão, pois,

Tentar compreender uma carreira ou uma vida como uma série única e em si suficiente de acontecimentos sucessivos sem outro elo que a associação a um 'sujeito' cuja constância não pode ser mais que a de um nome próprio socialmente reconhecido é quase tão absurdo quanto tentar explicar um trajeto no metrô sem levar em conta a estrutura da rede, isto e, a matriz das relações objetivas entre as diferentes estações (BOURDIEU, 2007, p. 189190).

É necessário compreender, também, a trajetória profissional e social de um indivíduo, em que pesa considerar especialmente o campo social que ele está inserido, o que remete ao conceito de habitus. Este se constitui como ações e reações reproduzidas pelos indivíduos, como um código estabelecido para convivência em sociedade, onde se deve seguir as regras ditadas para aquele determinado grupo social. Janowskl (2014 apud BOURDIEU, 2011, p. 83).

Nesse contexto, no início do século $X X$, à frente da Diretoria Geral de Saúde Pública, Osvaldo Cruz foi o médico responsável por inaugurar a nova era para a higiene e saúde nacional. Foram criadas organizações que tinham por ideal instituir medidas de caráter sanitário na promoção de saúde (GONDRA, 2000). Após a morte de Osvaldo Cruz, o médico sanitarista Carlos Chagas o sucedeu junto ao projeto de saneamento do país. Em seguida, tornou-se dirigente do Departamento Nacional de Saúde Pública (DNSP), desde sua fundação até 1926 (FINKELMAN, 2002). 
Nesse tempo, em 1921, Carlos Chagas aceitou a contribuição da Fundação Rockefeller para a modernização da saúde pública brasileira. Desse modo, exigia-se a formação de novos profissionais para atuar em prol da saúde pública. Nessa perspectiva, a intelectualidade médica entendia que "[...] a partir da criação de escolas especializadas para médicos e enfermeiras, a fiscalização da prática profissional e a organização de serviços de estatísticas para o país como um todo seriam as novas metas do DNSP" (HOCHMAN; LIMA, 1996, p. 196).

Diante da necessidade de formar profissionais que detivessem conhecimentos técnicos e científicos, nasceu o Serviço Nacional de Enfermeiras no DNSP (HOCHMAN, 2012). Em atendimento à solicitação do médico brasileiro, o Conselho Sanitário Internacional da Fundação Rockfeller enviou ao Brasil a enfermeira Norte Americana Ethel Parsons. Inicialmente, a enfermeira americana se dedicou a diagnosticar as prioridades relacionadas ao panorama nacional de saúde e necessidades de atenção de enfermagem. Além disso, organizou e dirigiu o primeiro serviço de formação de enfermeiras para a saúde pública no Distrito Federal em 1922 (OGUISSO et al., 2005).

A partir do contexto histórico e a necessidade de mudanças no perfil epidemiológico da saúde, ampliou-se o campo de atuação com a inserção das enfermeiras. Tais ações repercutiram na necessidade de formação em nível superior, pois "[...] não haveria como transformar o paradigma sanitário e o sistema de saúde sem atuar na formação dos profissionais" (FEUERWERKER; LIMA, 2002, p. 169).

Dessa forma, analisou-se parte da realidade social e a trajetória profissional de Opelina Rollemberg no sentido de compreender a inserção da mulher sergipana no campo do trabalho. Tem-se como cenário o início do século $X X$, momento em que a profissionalização feminina era restrita e pouco estimulada. Dentre as poucas profissões a que as mulheres tinham acesso, o magistério se constituía como o meio que permitia a profissionalização, neste caso, como enfermeira.

A protagonista desse estudo nasceu em 1906, na cidade de Capela, no estado de SergipeBrasil. Nosso estudo traz mais informações que evidenciam a presença marcante dessa mulher, professora normalista (1926) que trazia como anseio o cuidado para com os doentes, evidenciado na carta escrita para sua admissão na Escola de Enfermagem Anna Nery (EEAN), no Rio de Janeiro, em 1931 (UNIVERSIDADE FEDERAL DO RIO DE JANEIRO, 1934). Essa ação foi possível graças ao Diretor do Departamento de Saúde Pública de Sergipe, Dr. Jose Rodrigues Bastos Coelho, que conhecendo a qualidade do ensino da referida escola, esforçou-se para enviar moças sergipanas para serem formadas como enfermeiras diplomadas para que, ao retornarem, contribuíssem para o desenvolvimento da saúde no estado (SERGIPE, 1931).

Conforme afirma Burke (2011), o registro da história já se justifica por si só. No entanto, esta pesquisa contribui para além do registro histórico, pois traz elementos para o conhecimento e o reconhecimento da atuação de uma das pioneiras da enfermagem no Estado de Sergipe. A relevância deste estudo remete ao seu valor histórico para a enfermagem e para a história da saúde e da educação no Brasil. Além disso, os resultados da investigação acrescentarão informações históricas para a reflexão sobre o tema, que poderão se somar a outras pesquisas já desenvolvidas sobre a difusão do modelo nightingaleano no país, contribuindo para a historiografia da enfermagem como profissão, especialmente diante da carência de pesquisas nesse campo do saber em Sergipe.

\section{MÉTODO}

Trata-se de um estudo documental, descritivo, qualitativo e de caráter biográfico. Metodologicamente, elegeu-se a abordagem qualitativa pelo fato deste estudo lidar com interpretações das realidades sociais ao buscar revelar a trajetória profissional de Opelina Rollemberg, a fim de compreender o processo de organização da Saúde Pública de Sergipe e não valores estatísticos sobre a enfermagem (CRESWELL, 2010).

Na Enfermagem, a biografia ou trajetória de vida tem sido utilizada como um instrumento para ressaltar aspectos importantes da área profissional e das contribuições de seus agentes, que dedicaram suas vidas a assistência à saúde e a Educação, além de avaliar a progressão social e inovações teóricas para a profissão (PADILHA; NELSON; BORENSTEIN, 2011).

Inicialmente, para o estado da arte, foram consultadas bases de dados científicas como Scielo, Biblioteca Virtual da Saúde (BVS) e Pubmed. Tomou-se os primeiros indícios encontrados no artigo intitulado "As pioneiras e a 
consolidação da Enfermagem no Brasil" de (CARVALHO; SAUTHIER, 2004), sendo, em seguida, realizadas buscas sobre a história da enfermagem brasileira e sergipana. A partir desse encontro com o tema, foram identificados vestígios sobre a história da enfermeira diplomada do estado de Sergipe em três trabalhos científicos (VIEIRA; FARO, 2001; VIEIRA et al., 2002; MATTOS; CAMPOS, 2006). Estes, por sua vez, foram complementados por outras fontes documentais encontradas em diferentes locais de memória.

O levantamento documental no Centro de Documentação da Escola de Enfermagem Anna Nery, da Universidade Federal do Rio de Janeiro (CEDOC/EEAN/UFRJ), Biblioteca Estadual Epifânio Dória, Arquivo Público de Aracaju, Paróquia Nossa Senhora da Purificação em Capela-SE, cidade natal de Opelina Rollemberg. Nestes locais foram encontrados correspondências, ofícios, livros, jornais e o batistério que trouxeram novos dados sobre a história do desenvolvimento de Sergipe, incluindo informações sobre a saúde no Estado e sobre a referida enfermeira.

Ressalta-se que não foi necessária a aprovação de um Comitê de Ética em Pesquisa (CEP) por se tratar de uma investigação estritamente documental, cujas fontes estão disponíveis em centros de pesquisa abertos ao público para consultas. Entretanto, foram observadas as normas específicas de cada arquivo consultado, seguindo-se assim as orientações estabelecidas por eles no que tange à coleta, ao armazenamento e a divulgação dos dados.

As informações colhidas até o momento, que fazem parte da dissertação em andamento, foram reunidas e agrupadas em categorias que aqui abordam fases importantes da trajetória profissional da professora e enfermeira Opelina Rollemberg como: nascimento, curso de normalista, a admissão no Grupo Escolar Barão de Maruim, a Graduação em Enfermagem pela EEAN e a trajetória profissional no Departamento de Saúde Pública de Sergipe.

\section{RESULTADOS E DISCUSSÃO}

Opelina Rollemberg nasceu em 14 de agosto de 1906, na cidade de Capela, interior de Sergipe, sendo filha de Juvenal Rollemberg e Maria Almeida Rollemberg. Foi batizada pelo Padre Leandro Ribeiro dos Santos na Paróquia Nossa Senhora da Purificação, na referida cidade, no dia 4 de novembro de 1906, tendo como padrinhos José da Trindade e Opelina de Carvalho Trindade (PARÓQUIA NOSSA SENHORA DA PURIFICAÇÃO, 1906.)

Em 1919, cursou um ano para conclusão do ensino básico. Em 1920, ingressou no curso de complementação para admissão na Escola Normal. De acordo com o mesmo documento, em 7 de dezembro de 1925, a aluna Opelina Rollemberg concluiu o ensino médio na Escola Normal Ruy Barbosa, localizada na cidade de Aracaju/SE (UNIVERSIDADE FEDERAL DO RIO DE JANEIRO, 1934).

Condizente com as especificações da ficha de Inscrição, verificou-se no Diário Oficial do Estado de Sergipe a nomeação de Opelina Rollemberg como professora normalista diplomada pela Escola Normal Ruy Barbosa de Aracaju. Esse documento informa que a mesma foi convocada para ser professora adjunta durante 2 anos no Grupo Escolar Barão de Maruim, pelo então governador Maurício Graccho Cardoso (1874-1950), em 19 de fevereiro de 1926. Nesse mesmo documento, identificou-se as disciplinas cursadas, entre elas Psicologia e História Natural, que certamente contribuíram para o acesso à Graduação em Enfermagem e, consequentemente, na sua atuação como enfermeira (SERGIPE, 1926).

Observa-se na ficha de Inscrição da EEAN consta que, além de ser professora, Opelina Rollemberg também atuou como guarda-livros durante 9 (nove) meses em local não mencionado. No mesmo documento, verifica-se outra habilidade dela, pois trabalhou como caixa durante 7 meses em outro comércio local, que também não foi mencionado no referido documento (UNIVERSIDADE FEDERAL DO RIO DE JANEIRO, 1934). 
Figura 01. Ficha de Inscrição de Opelina Rollemberg na EEAN.

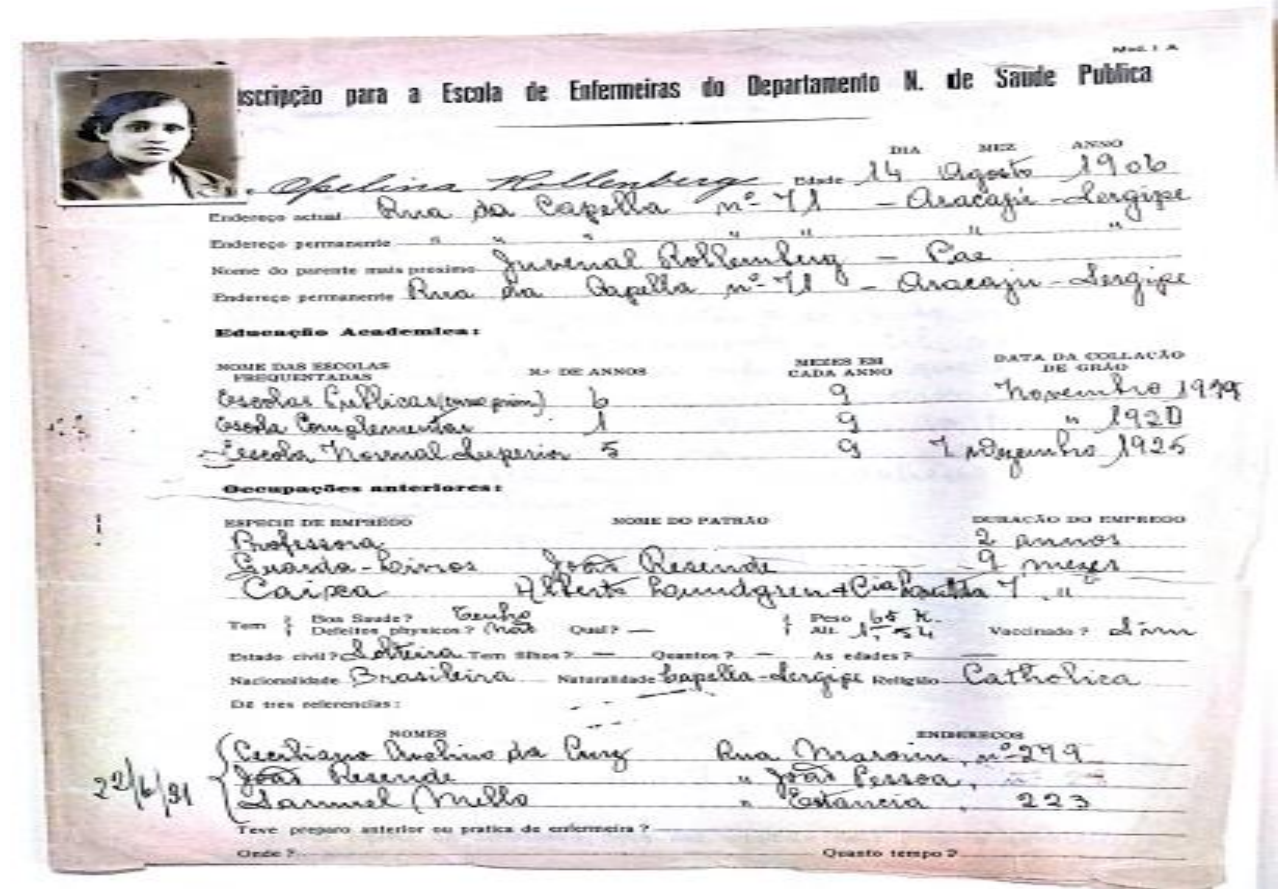

Fonte: UNIVERSIDADE FEDERAL DO RIO DE JANEIRO (1934).

\section{Processo formativo, trajetória profissional e contribuições à enfermagem sergipana.}

Ressalta-se que a enfermagem profissional sergipana teve início a partir da criação do Departamento de Saúde Pública de Sergipe pelo decreto no 48 de 16 de maio de 1931, assinado pelo Interventor federal do estado, Augusto Maynard Gomes (DIÁRIO OFICIAL DO ESTADO DE SERGIPE, 1931). Entretanto, anterior ao decreto, foi nomeado como diretor o Dr. Jose Rodrigues Bastos Coelho e, com o apoio do Dr. Simeão Vieira Sobral que, conhecendo o ensino da Escola de Enfermagem Anna Nery (EEAN) no Rio de Janeiro, começava a fazer a propaganda nos Jornais e Diário Oficial ainda em abril do mesmo ano, convidando as moças que se enquadrassem nas exigências da referida escola a se matricularem. Assim, foram enviadas ao Rio de Janeiro, a partir de julho, 8 (oito) mulheres, entre elas Opelina Rollemberg, para que realizassem sua formação superior na referida escola e, ao retornarem a Sergipe, trabalhassem na organização dos Serviços de Saúde do estado (DIÁRIO OFICIAL DO ESTADO DE SERGIPE, 1931a).

Seguindo com as investigações, foram encontrados nas bases Scielo e Pubmed, e na ABEn-SE, os três trabalhos citados anteriormente. As três fontes indiretas fazem menção a personagem de forma bastante pontual, mas que dão pistas da relação de Opelina Rollemberg com o desenvolvimento da Enfermagem Sergipana. O primeiro trabalho foi de Vieira e Faro (2001) que descreve sobre a Associação Brasileira de Enfermagem (ABEn-SE) nos 47 anos da sua fundação e apresenta alguns aspectos que contribuíram para a criação da seção Sergipe, a organização dos serviços de Saúde no estado e instituições, como também algumas dificuldades, e cita a participação de Opelina Rollemberg.

Em 12/04/1954 o grupo de enfermeiras, presidida por Isabel C. Macintyre, diretora da EAE do Hospital de Cirurgia, cria a diretoria provisória da ABEn Sergipe com o fim de organizá-la e eleger sua diretoria. Um mês depois tomou posse a 1a diretoria, tendo como presidente Opelina Rollemberg (VIEIRA; FARO, 2001, p. 386).

O segundo trabalho foi o livro ABEn-SE: 52 anos de Vontade, Coração e Garra, de Mattos e Campos (2006), que posteriormente publicaram um relato de experiência com o mesmo título em 2011, no qual descrevem que:

A história da ABEn-SE está
intimamente ligada a


história da enfermagem e da saúde em Sergipe. Alguns fatos e circunstancias culminaram na criação dessa seção que passou a coordenar, a partir desse momento, os destinos e até a vida social dos profissionais da enfermagem no estado. Nos períodos de 1931 a 1954 ocorrem fatos relevantes no cenário da enfermagem e que merecem destaque: a criação do Departamento de Saúde Pública de Sergipe; em 1937 o nosso estado recebe a sua primeira enfermeira profissional, D. Opelina Rollemberg, graduada em enfermagem na Escola Ana Néri - Rio de Janeiro, onde integrava o quadro de funcionários do Ministério da Saúde (MATTOS; CAMPOS, 2006, p. 21).

No mesmo sentido, Mattos e Campos (2006) citam sobre o trabalho intitulado "O Início da enfermagem profissional em Sergipe: Opelina Rollemberg", que descreve uma informação importante:

No dia 5 de abril de 1966 a Associação perde uma figura importante da Enfermagem, uma vez que falece a primeira enfermeira do Estado de Sergipe, Opelina Rollemberg, que era portadora da doença de Chagas. Antes do seu falecimento a presidente da ABEn-SE, Osa M.a Machado de Araújo, solicitou às colegas que a visitassem e se revezassem no cuidado a
D. Opelina, conforme costume da época. Mattos; Campos(2006 apud VIEIRA et al. 2002, p. 9).

Corroboramos a afirmação de Le Goff (1994, p. 545) de que "[...] só a análise do documento enquanto monumento permite à memória coletiva recuperá-lo e ao historiador usá-lo cientificamente, isto é, com pleno conhecimento de causa". Assim, a partir das fontes analisadas que apontam Opelina Rollemberg como a primeira enfermeira diplomada do estado de Sergipe, buscou-se fontes para delimitar sua trajetória de formação e atuação profissional.

Ao analisar os dossiês das primeiras turmas formadas na EEAN (1923-1925) encontramos o registro de uma aluna que declarava em sua ficha de inscrição ser do estado de Sergipe. Seu nome é Noelia Almeida Costa, iniciou a graduação em enfermagem 19 de fevereiro de 1923 e concluiu o curso em 19 de junho de 1925, sendo ela a primeira enfermeira diplomada pela EEAN, entretanto não foi encontrado nenhum registro da atuação de Noelia no seus estado natal, enquanto que Opelina, graduada em 1934, retornou para seu estado de origem contribuindo consubstancialmente para o desenvolvimento da saúde pública e da enfermagem sergipana. (UNIVERSIDADE FEDERAL DO RIO DE JANEIRO, 1927).

Quanto à professora Opelina Rollemberg, a mesma participou do processo seletivo da terceira turma (1931-1934) do curso de Enfermagem da Escola de Enfermagem Anna Nery (EEAN), conforme relato escrito a próprio punho na ficha de admissão em 14 de junho de 1931. Entretanto, identificou-se, a partir deste documento, que Opelina já ofertava os cuidados de enfermagem antes mesmo da sua formação que, aqui, entende-se como sendo o fato que a motivou a fazer a graduação, considerada na época como uma missão reservada às mulheres. 
Figura 2. Solicitação de ingresso na Escola de Enfermagem Anna Nery.

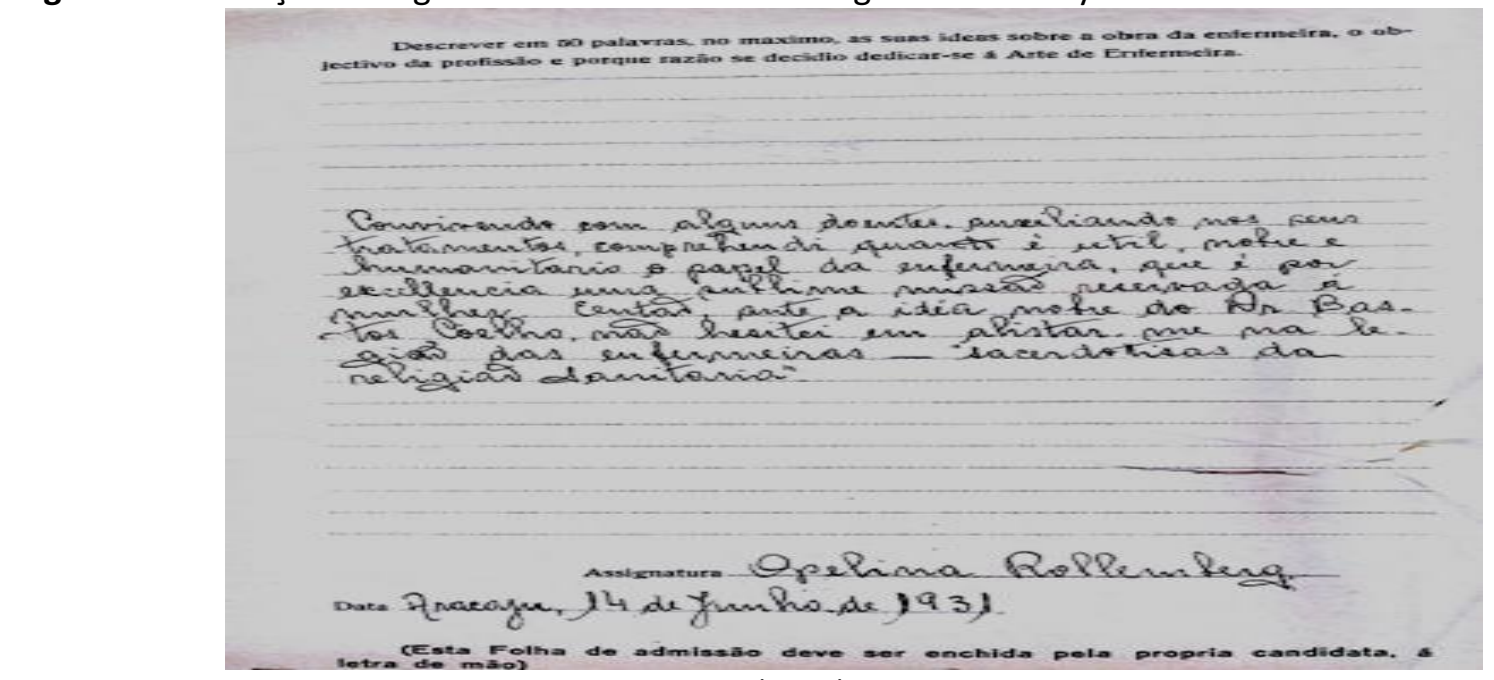

Fonte: UNIVERSIDADE FEDERAL DO RIO DE JANEIRO (1934).

Quadro 1. Criado pelos pesquisadores com a transcrição das informações na íntegra da figura 2.

Convivendo com alguns doentes, auxiliando nos seus tratamentos, compreendi quanto é útil, nobre e humanitário o papel da enfermeira, que é por excelência uma sublime missão reservada a mulher. Então, ante a ideia nobre do Dr. Bastos Coelho, não hesitei em alistar-me na legião das enfermeiras sacerdotisas da religião sanitária.

Fonte: Autores (2019)

O curso de enfermagem durava o período de 33 (trinta e três) meses letivos (2 anos e 9 meses), mas devido aos recessos durante as disciplinas, totalizava 3 anos. Nessa época, a escola era dirigida pela norte-americana Bertha Lucile Pullen, no período de 1933 a 1938, a qual não mediu esforços para a formação das enfermeiras brasileiras de forma rigorosa, baseando-se na ética e no profissionalismo, mas, sobretudo, com autonomia, além de não se deixar influenciar pelas exigências do poder econômico (PADILHA; NELSON; BORENSTEIN, 2011).

No currículo das enfermeiras constavam disciplinas de enfermagem prática e teórica, clínica aplicada, anatomia e fisiologia, drogas e soluções, microbiologia, história da enfermagem, ética, higiene (pessoal, infantil e saúde pública), massagem, ginástica, aplicação a ataduras, psicologia, dietética, matéria médica, patologia interna e externa, obstetrícia e ginecologia, doenças contagiosas, primeiros socorros, enfermagem em saúde pública e psiquiatra, sentidos especiais, doenças venéreas, etc.
(UNIVERSIDADE FEDERAL DO RIO DE JANEIRO, 1934).

Nesse contexto, a partir do modelo de avaliação da época, nota-se o rigor e a responsabilidade exigida às alunas. Assim, acredita-se que Opelina Rollemberg foi uma estudante muito dedicada aos processos de aprendizado da instituição de ensino. Logo, tornou-se aluna remunerada, ou seja recebeu bolsa de estudos, dada pelo governo, durante o período de 1 de janeiro de 1932 a 8 de julho de 1934, totalizando 2 anos, 6 meses e 10 dias. Após conclusão do curso em 1934, desempenhava o papel de instrutora de alunas da EEAN, entendido aqui que a referida enfermeira se adaptou bem a uma das suas funções, como a docência, caso contrário, não teria sido convidada (UNIVERSIDADE FEDERAL DO RIO DE JANEIRO, 1934). Neste sentido, "[...] um indivíduo que não tem as características ou não consegue adaptar o habitus para o convívio em grupo será excluído do campo por não possuir pertencimento a esse" (JANOWSKI, 2014, p. 3).

Neste sentido, analisa-se a função e a importância da escola para a formação do alunado, visto que é a escola que vai moldar o aluno dentro das suas regras e, consequentemente, após a sua formação, irá reproduzir nas suas práticas pedagógicas a formação adquirida. Para compreender o papel da escola, ou seja, campo social que dita regras, é necessário buscar as fontes na referida instituição, na tentativa de reconstituir uma historiografia que esclareça como se deu o processo de formação das enfermeiras. 
[...] Pelo fato de que o trabalho pedagógico (seja ele exercido pela Escola, por uma Igreja ou um Partido) tem por efeito produzir indivíduos modificados de forma durável, sistemática por uma ação prolongada de transformação que tende a dotá-los de uma mesma formação durável e transferível (habitus) ,isto é, de esquemas comuns de pensamento, de percepção, de apreciação e de ação, pelo fato de que a produção em série de indivíduos identicamente programados exige e suscita historicamente a produção de agentes de programação eles mesmos identicamente

programados e de
instrumentos padronizados de conservação e de transmissão; pelo fato de que a duração necessária para que uma transformação

sistemática da ação de transformação é ao menos igual ao tempo indispensável para produzir em série

\section{reprodutores}

transformados, isto é, agentes capazes de exercer uma ação transformadora

reprodutora da formação que eles próprios receberam (BOURDIEU, 2012, p. 79).

Diante das necessidades de organização pelo qual Sergipe passava, reflexo do desenvolvimento nacional, principalmente na área da saúde, era necessária a atuação de profissionais de saúde, como médicos e enfermeiras. Assim, a enfermeira Opelina Rollemberg foi convocada a integrar o quadro do Departamento Nacional de Saúde Pública e retornar ao seu estado de origem. Porém, ocorreram tensões para seu retorno devido ao fato de a referida enfermeira, após a conclusão do curso, ter se tornado instrutora de alunas da EEAN. Além disso, a direção da escola negou a sua liberação, devido ao fato de um número significativo de enfermeiras estarem de licença ou liberadas para a realização de outros serviços. A dispensa dela implicaria na impossibilidade de contratação de substituta, pois a vaga estaria ocupada por Opelina. Ademais, as instrutoras remanescentes ficariam sobrecarregadas, prejudicando a aprendizagem das alunas (UNIVERSIDADE FEDERAL DO RIO DE JANEIRO, 1934).

Figura 3. Ofício expedido pela Diretora da Escola Anna Nery.

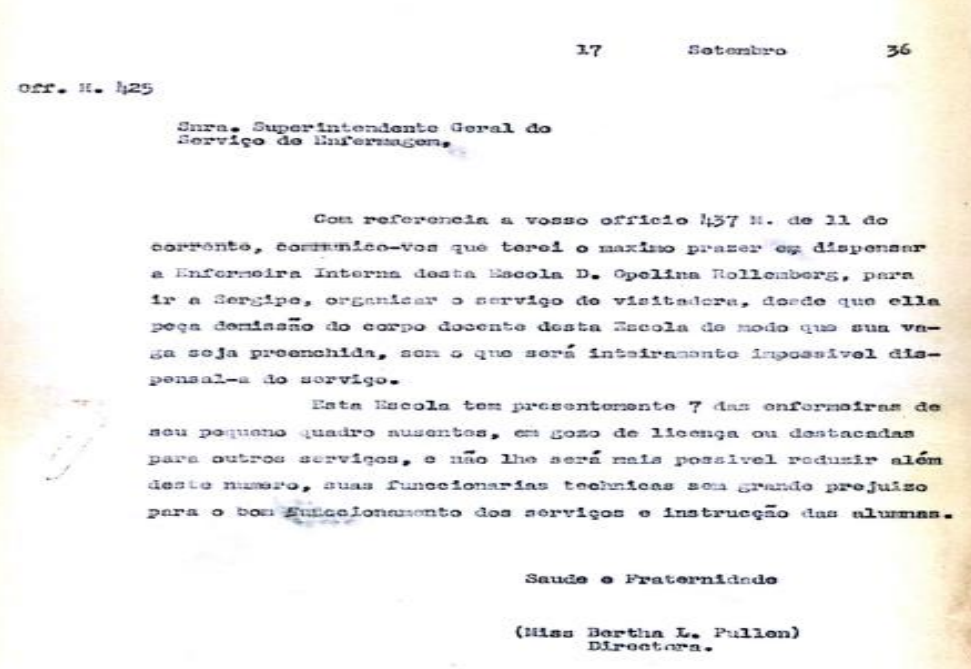

Fonte: UNIVERSIDADE FEDERAL DO RIO DE JANEIRO (1934). 
Quadro 2. Criado pelos pesquisadores com a transcrição das informações na íntegra da figura 3.

\section{Off. N. 425}

Snra. Superintendente Geral do Serviço de Enfermagem.

Com referência a vosso officio N. 437 de 11 do corrente, comunico-vos que terei o máximo prazer de dispensar a Enfermeira interna desta Escola D. Opelina Rollemberg, para ir a Sergipe, organizar o serviço de visitadora, desde que ela peça demissão do corpo docente desta Escola de modo que sua vaga seja preenchida, sem o que será inteiramente impossível dispensá-la do serviço.

Esta Escola tem presentemente 7 das enfermeiras de seu pequeno quadro ausentes, em gozo de licença ou destacadas para outros serviços, e não lhe será mais possível reduzir além deste número, suas funcionarias technicas sem grande prejuízo para o bom funcionamento dos serviços e instrução de alunas.

Saúde e Fraternidade (Miss Bertha L. Pullen) Diretora.

Fonte: Autores (2019)

Diante do senso de cumprimento do dever Opelina, retornou a Sergipe em 1937. Suas atribuições iniciais eram implementar a formação e supervisão do serviço das enfermeirasvisitadoras. As futuras profissionais teriam como missão a educação em saúde das famílias em seus domicílios, a fim de ampliar a proposta nacional de prevenção e combate às doenças da época (varíola, febre amarela, malária, tuberculose, sífilis, lepra) (SERGIPE, 1931-b).

Dessa forma, entende-se que a então enfermeira Opelina Rollemberg iniciou a sua trajetória profissional como docente na EEAN. Contudo, conforme citado anteriormente, o objetivo do apoio do Interventor ao enviar as moças sergipanas para cursar enfermagem era que, após a conclusão do curso, elas retornassem ao estado para servirem como pioneiras na organização dos serviços de saúde e de enfermagem (SERGIPE, 1931-b). Assim, a referida enfermeira foi convocada a integrar o quadro do Departamento Nacional de Saúde Pública (DNSP).

Entretanto, foi possível notar que ocorreram tensões para a seu retorno ao estado, sendo necessário a autorização do Presidente da República Getúlio Vargas, isto porque Opelina Rollemberg, após a conclusão do curso, tornou-se docente da EEAN. A diretora Bertha Pullen argumentou que teria o máximo de prazer em dispensar a enfermeira, com a condição de que
Opelina pedisse demissão do corpo docente, sendo sua vaga preenchida, caso contrário, não seria possível dispensá-la. De modo que, somente retornou a Sergipe em 25 de novembro de 1937, após insistentes solicitações do Departamento de Saúde Pública do estado ao DNSP e à EEAN, a fim de organizar o serviço de enfermeiras-visitadoras (UNIVERSIDADE FEDERAL DO RIO DE JANEIRO, 1934).

Portanto, as primeiras contribuições da enfermeira sergipana Opelina Rollemberg para o Estado se referem à organização e a implementação de todo um modelo de saúde pública, assim como à formação de profissionais a partir do curso de enfermeiras-visitadoras que iriam adentrar às casas das famílias e educar sobre as práticas sanitaristas e de enfermagem no sentido de debelar a falta de higiene e, assim, prevenir parte das epidemias da época. Inicialmente, a enfermeira ficaria por um período de seis meses, no entanto, sua estada prolongouse até 20 de janeiro de 1942, quando foi informada, por meio de um telegrama do Departamento de Saúde Pública de Sergipe, que a partir daquele momento seria transferida para a 5a Delegacia Federal da quinta região junto à Diretoria de Saúde do estado de Alagoas para exercer a mesma função (UNIVERSIDADE FEDERAL DO RIO DE JANEIRO, 1934).

\section{CONSIDERAÇÕES FINAIS}

Conclui-se que a trajetória profissional de Opelina Rollemberg (1937-1942), considerada uma das pioneiras da enfermagem sergipana, contribuiu de forma significativa para a saúde em Sergipe a partir do curso de enfermeirasvisitadoras. Seus reflexos se deram na construção e implementação do modelo de saúde pública, sendo o modelo de Atenção Primária atualmente compreendido como um dos resultados significativos do trabalho dos gestores e de Opelina Rollemberg na enfermagem. A atuação da personagem foi bastante positiva que foi requisitada para ajudar em outros estados do Nordeste.

Espera-se contribuir para enfermagem brasileira e, sobretudo, para o campo da História da Educação, base desta pesquisa, no qual se destaca não somente os percursos educacionais e a evolução das práticas pedagógicas e de seus agentes, mas também permite compreender o contexto em que ocorreram. 


\section{REFERÊNCIAS}

AMORIM, S. S. A trajetória de Alfredo Montes, 1848-1906: representações da configuração do trabalho docente no ensino secundário em Sergipe. São Cristóvão: Editora UFS; Aracaju: Fundação Oviêdo Teixeira, 2009.

BOURDIEU, P. A ilusão biográfica. In: AMADO, J.; FERREIRA, M. (Org.). Usos e abusos da história oral. Rio de Janeiro: Fundação Getúlio Vargas; 1996. p. 183.

BOURDIEU, P. A economia das trocas simbólicas. São Paulo: Perspectiva, 2007. (Coleção estudos; 20 - dirigida por J. Guinsburg).

BOURDIEU, P. A reprodução: elementos para uma teoria do sistema de ensino, 5. ed., Petrópolis, RJ: Vozes, 2012.

BURKE, P. (org.). A Escrita da História. São Paulo: Editora UNESP, 2011.

CARVALHO, V; SAUTHIER, J. As pioneiras e a consolidação da enfermagem no Brasil: documentos históricos da EEAN/UFRJ - 1932 a 1950. Rio de Janeiro: Anna Nery, 2004, p. 16. Disponível em:

http://biblioteca.cofen.gov.br/wp-

content/uploads/2014/07/As-pioneiras-e-aconsolidacao-da-enfermagem-no-Brasil.pdf.

Acesso em: 20 set. 2017.

CHARTIER, R. A História Cultural: entre práticas e representações. Lisboa: DIFEL, 1990.

CRESWELL, J.W. Projeto de Pesquisa: métodos qualitativos, quantitativo e misto. 3. ed. Porto Alegre: Artmed, 2010.

FEUERWERKER, L. C. M.; LIMA, V. V. Os Paradigmas de atenção à saúde e da formação de recursos humanos. In: BRASIL. Ministério da Saúde. Política de recursos humanos em saúde. Brasília: Ministério da Saúde, 2002. p. 169-178.

FINKELMAN, J. (Org.). Caminhos da saúde no Brasil. Rio de Janeiro: Editora Fiocruz, 2002. Disponível em: http://books.scielo.org/id/sd/pdf/finkelman9788575412848.pdf. Acesso em: 30 set. 2017. https://doi.org/10.7476/9788575412848
GONDRA, J. G. A Sementeira do Provir: higiene e infância no século XIX. Educação e Pesquisa, São Paulo, v. 26, n. 1, p. 99-117, jan./jun. 2000. Disponível em: http://www.revistas.usp.br/ep/article/view/278 35/29607. Acesso em: 27 set. 2017. https://doi.org/10.1590/S1517$\underline{97022000000100008}$

HOCHMAN, G. A era do saneamento: as bases da política de saúde pública no Brasil. 3. ed. São Paulo: Hucitec, 2012.

HOCHMAN, G.; LIMA, N. Condenado pela raça, absolvido pela medicina: o Brasil descoberto pelo Movimento Sanitarista da Primeira república. Rio de Janeiro, Fiocruz, 1996.

JANOWSKI, D. A teoria de Pierre Bourdie: Habitus, campo social e capital cultural. VIII Jornadas de Sociología de la UNLP, Memoria Académica. Ensenada, Argentina, 2014. Disponível em:

http://www.memoria.fahce.unlp.edu.ar/trab_eve ntos/ev.4639/ev.4639.pdf. Acesso em: 30 nov. 2018.

LE GOFF, J. História e memória. Campinas, SP: Editora da UNICAMP, 1994. (Coleção Repertórios).

MATTOS, M.C.T; CAMPOS, M.P.A. ABEn-SE: 52 anos de Vontade, Coração e Garra. Aracaju: Texto Pronto Gráfica e Editora Ltda, 2006.

NÓVOA, A. Inovação e história da educação: Teoria e Educação. Porto Alegre: Pannonica, 1992, p. 211. (Dossiê: História da Educação, 6).

OGUISSO, T. et al. Trajetória histórica e legal da Enfermagem. 2. ed. Barueri: Manole, 2005.

PADILHA, M. I.; NELSON, S.; BORENSTEIN M. S. As biografias como um dos caminhos na construção da identidade do profissional da enfermagem. História, Ciências, Saúde Manguinhos, Rio de Janeiro, v. 18, supl. 1, p. 241-252., dez. 2011. Disponível em: http://www.scielo.br/pdf/hcsm/v18s1/13.pdf. Acesso em: 19 set. 2018. https://doi.org/10.1590/S010459702011000500013 
PARÓQUIA NOSSA SENHORA DA PURIFICAÇÃO SERGIPE. Livro de Registros de Batizados (19031908), n. 11. p. 293.

SERGIPE (Estado). Seção do Poder Executivo, Diário oficial do estado de Sergipe, Aracaju, v. 19, n. 7.009, fev. 1926, p. 03. Disponível em: (Arquivo Físico) Arquivo Público Municipal de Aracaju- SE, Pacotilha JDE- 23. Acesso em: 05 jul. 2018.

SERGIPE (Estado). Decreto no 48 de 16 de maio de 1931 - Cria o Departamento de Saúde Pública de Sergipe e baixa o respectivo regulamento). Pacotilha LDS V17 D09. Diário oficial do estado de Sergipe, Aracaju, v. 13, n. 330, de 20 maio de 1931-a. Disponível em: (Arquivo Físico), Arquivo Público do Estado de Sergipe. Acesso em: 28 jun. 2018.

SERGIPE (Estado). Seção do Poder Executivo, Diário oficial do estado de Sergipe, Aracaju, v. 13, n. 3340, de jul de 1931-b, p. discrim24887. Pacotilha LDS V17 D09- Disponível em: (Arquivo Físico) Arquivo Público do Estado de Sergipe. Acesso em: 28 jun. 2018.

UNIVERSIDADE FEDERAL DO RIO DE JANEIRO. Centro de Documentação da Escola de Enfermagem Anna Nery - UFRJ/CEDOC/EEAN. Coleção de Informações Técnico Profissionais SERVIR. v. 1; Módulo GR, Caixa 07, 1927.

UNIVERSIDADE FEDERAL DO RIO DE JANEIRO. Centro de Documentação da Escola de Enfermagem Anna Nery - UFRJ/CEDOC/EEAN Coleção de Informações Técnico Profissionais SERVIR. v.1, Módulo GR, Caixa 11, 1934.

VIEIRA, M. J.; FARO, C. M. M. S. ABEn SERGIPE: 47 anos de Luta e Resistência. Revista Brasileira de Enfermagem. Brasília, v. 54, n. 2, p. 382-388, abr./jun., 2001. Disponível em: http://www.scielo.br/scielo.php?script=sci_arttex t\&pid=S0034-

$71672001000200026 \& \operatorname{lng}=p t \& t \operatorname{lng}=p t .>\quad$ Acesso em: 12/09/2018. https://doi.org/10.1590/S0034$\underline{71672001000200026}$

VIEIRA, M. J. et al. O Início da enfermagem profissional em Sergipe: Opelina Rollemberg. In: ENCONTRO DE ENFERMAGEM DO NORDESTE, Aracaju,2002. Anais XVIII Encontro de
Enfermagem do Nordeste (impresso), Aracaju: Associação Brasileira de Enfermagem, sessão Sergipe (ABEn-SE), 2002. p. 53-54. 